\title{
Replication of the Association between Copy Number Variation on 8p23.1 and Autism by Using ASD-specific BAC Array
}

\author{
Jung Hoon Woo', Song-Ju Yang ${ }^{1}$, Seon-Hee \\ $\mathrm{Yim}^{2}$, Hae-Jin $\mathrm{Hu}^{2}$, Myung-Ju Shin', Eun-Hee \\ $\mathrm{Oh}^{1}$, Hyun-Woong Kang ${ }^{1}$, Seonyang Park ${ }^{3}$ and \\ Yeun-Jun Chung ${ }^{2 *}$
}

${ }^{1}$ Macrogen, Inc., Seoul 153- 781, Korea, ${ }^{2}$ Intergrated Research Center for Genome Polymorphism, Department of Microbiology, The Catholic University of Korea School of Medicine, Seoul 137-701, Korea, ${ }^{3}$ Department of Internal Medicine, Seoul National University College of Medicine, Seoul 110-744, Korea

\begin{abstract}
To discover genetic markers for autism spectrum disorder (ASD), we previously applied genome-wide BAC array comparative genomic hybridization (array-CGH) to 28 autistic patients and 62 normal controls in Korean population, and identified that chromosomal losses on $8 p 23.1$ and on $17 p 11.2$ are significantly associated with autism. In this study, we developed an 8.5K ASD-specific BAC array covering 27 previously reported ASD-associated CNV loci including ours and examined whether the associations would be replicated in 8 ASD patient cell lines of four different ethnic groups and 10 Korean normal controls. As a result, a CNV-loss on 8p23.1 was found to be significantly more frequent in patients regardless of ethnicity $(p<0.0001)$. This CNV region contains two coding genes, DEFA1 and DEFA3, which are members of DEFENSIN gene family. Two other CNVs on $17 \mathrm{p} 11.2$ and $\mathrm{Xp22.31}$ were also distributed differently between ASDs and controls, but not significant $(p=0.069$ and 0.092 , respectively). All the other loci did not show significant association. When these evidences are considered, the association between ASD and CNV of $D E F E N S I N$ gene seems worthy of further exploration to elucidate the pathogenesis of ASD. Validation studies with a larger sample size will be required to verify its biological implication.
\end{abstract}

Keywords: 8p23.1, array-CGH, autism, copy number variation, defensin

*Corresponding author: E-mail yejun@catholic.ac.kr Tel +82-2-2258-7343, Fax +82-2-596-8969 Accepted 4 March 2010

\section{Introduction}

Autism spectrum disorder (ASD) is neurodevelopmental syndrome with a broad spectrum of phenotypes including profound deficits in social relatedness and communication, repetitive behaviors, and restricted interests (Rutter, 2005). There is accumulating evidence which suggests substantial genetic contribution to ASD development (Folstein and Rosen-Sheidley, 2001; VeenstraVanderWeele and Cook, 2004). For example, the concordance rate of autism was significantly higher in monozygotic twins than in dizygotic twins (Folstein and Rosen-Sheidley, 2001; Veenstra-VanderWeele and Cook, 2004). Although previous studies including linkage analyses have revealed a number of potential ASD-associated loci, genetic and phenotypic heterogeneity of the disease has made it difficult to replicate the results as well as to identify ASD-associated genetic mechanisms (Folstein and Rosen-Sheidley, 2001; Klauck, 2006; Veenstra-VanderWeele and Cook, 2004).

Recently a new type of human genetic variation named copy number variant (CNV) has been suggested as one of the major sources of genomic diversity ranging from normal phenotypic heterogeneity to disease susceptibility (Freeman et al., 2006; lafrate et al., 2004; Sebat et al., 2004). Indeed, lines of evidence have been reported which demonstrated the association between CNV and ASD (Cho et al., 2009; Cook and Scherer, 2008; Glessner et al., 2009; Marshall et al., 2008; Sebat et al., 2007). In our previous study, we identified 38 copy number variable regions in ASD patients, two of which (CNVs on 8p23.1 and 17p11.2) were found to be significantly associated with ASD (Cho et al., 2009).

Using 27 CNV loci previously reported to be associated with ASD including ours, we developed an $8.5 \mathrm{~K}$ ASD-specific BAC array and screened whether the association between those CNVs would be replicated in patient cell lines of four different ethnic groups.

\section{Methods}

\section{Study samples}

We used DNA extracted from B-lymphocyte cell lines of 8 ASD patients of four different ethnicities; Caucasian, Chinese, Asiatic Indian, and Hispanic (Coriell Institute for Medical Research, Camden, NJ, USA). General characteristics of the 8 ASD patients are shown in Table 1. As 
normal control subjects, we used 10 normal Korean adults without any sign of ASD and other genetic disorders. Using the D5500A PUREGENE DNA Isolation kit (QIAGEN, Valencia, CA, USA), we extracted genomic DNA from the blood of controls according to manufacturer' $s$ instructions. DNA quantity and quality were checked by a NanoDrop assay and $1 \%$ agarose gel electrophoresis. This study was performed under the approval of the Institutional Review Boards of The Catholic University of Korea (CUMC07U025).

\section{Preparation of autism-specific BAC array proto- type}

In total, 846 BAC clones representing the 27 candidate CNV regions were selected from the DNA BAC library (Macrogen, Seoul, Korea) and the BAC clone DNA was extracted as described elsewhere (Cho et al., 2009; Chung et al., 2004). In brief, each BAC clone was isolated, grown in $500 \mathrm{ml}$ of culture media, pelleted, from which DNA was extracted using an alkaline lysis method. All selected clones were bi-directionally sequenced using the ABI PRISM 3700 DNA Analyzer (Applied Biosystems, Foster City, CA, USA), and their sequences were blasted and mapped according to their linear positions. Extracted BAC DNA was dissolved in $50 \%$ DMSO with a concentration of $400 \sim 500 \mathrm{ng} / \mathrm{ul}$ and spotted in triplicate onto the glass by the Genemachines OmniGrid 100 arrayer (Digilab Genomic Solutions, Holliston, MA, USA). We used Corning UltraGAPS amine coating slides (Corning, Acton, MA, USA) and Telecam SMP4 pins (Arrayit Corporation, Sunnyvale, CA, USA) for DNA spotting. We followed processes for a general contact type spotter.

\section{Array-CGH experiment}

Array-CGH was performed as described elsewhere using the MAUl hybridization station (BioMicro Systems, Salt Lake City, Utah, USA) (Joo et al., 2008). In one tube, Cy3-labeled sample and Cy5-labeled reference DNAs were mixed together and $50 \mu \mathrm{g}$ human Cot I DNA (HybMasker, ConnectaGen, Seoul, Korea), $20 \mu \mathrm{l}$ of $3 \mathrm{M}$ sodium acetate and $600 \mu \mathrm{l}$ of cold $100 \%$ ethanol were added to precipitate DNA. The obtained pellet was re-suspended in $40 \mu \mathrm{l}$ of hybridization solution containing $50 \%$ formamide, $10 \%$ dextran sulfate, 2 SSC, $4 \%$ SDS and 200 ug of yeast tRNA. Hybridization was performed in slide chambers for $48 \mathrm{hr}$ at $37 \mathrm{C}$. After the hybridization, slides were washed serially at room temperature in solution 1 (2X saline-sodium citrate (SSC), $0.1 \%$ SDS) for $10 \mathrm{~min}(1 \mathrm{X})$, in solution $2(0.1 \mathrm{X} \mathrm{SSC}, 0.1 \%$ SDS) for $10 \mathrm{~min}(2 \mathrm{X})$ and in solution $3(0.1 \mathrm{XSC})$ for $1 \mathrm{~min}(3 \mathrm{X})$ followed by rinsing in distilled water for 10 $\mathrm{sec}$. Finally, the slides were spin-dried for $2 \mathrm{~min}$ at 1000 $\mathrm{rpm}$. All the experiments were duplicated and dyeswapping was done for more reliable interpretation.

\section{Copy number analysis}

Arrays were scanned and analyzed using the GenePix 4200A two-color fluorescent scanner (MDS Analytical Technologies, Sunnyvale, CA, USA) and the images were processed using the MacViewer 1.6 imaging software (Macrogen, Seoul, Korea). Signal intensity ratios (test/reference) were measured and converted to log2 scale. Background corrected signal intensity ratios were normalized using Lowess normalization. For defining CNVs, we set the cut-off values of signal intensity ratios at above 0.25 (log2 scale) for copy number gain and at below -0.25 for copy number loss according to our previous study (Cho et al., 2009; Jeong et al., 2008). We also analyzed dye-swap experiment results to get more reliable CNV call. If a CNV call is true, its test/reference intensity ratio value must be inverted by switching the dyes. Only the original ratios and inverted dye swap signals were observed, the according CNV was called as a true one.

Table 1. General characteristics of 8 ASD patients

\begin{tabular}{lrlll}
\hline \multicolumn{2}{l}{ Sample ID } & Age (year) & Sex & \multicolumn{1}{c}{ Ethnicity } \\
\hline AU10000 & 6 & Male & Caucasian & Remarks \\
AU10010 & 12 & Female & Caucasian & - \\
AU10063 & 6 & Male & Other* & Pervasive developmental disorder \\
AU10078 & 7 & Female & Other & - \\
AU10090 & 2 & Male & Asiatic Indian (East Indian) & Pervasive developmental disorder \\
AU10114 & 5 & Male & Asian (Chinese) & Pervasive developmental disorder \\
AU10115 & 4 & Male & Asian (Chinese) & Pervasive developmental disorder \\
AU10184 & 10 & Male & Hispanic/Latino & - \\
\hline
\end{tabular}

*Other indicates that the sample was not specified in sample overview of Coriell Cell Repositories. 


\section{Statistical Analysis}

We used Stata version 10.0 (Stata Corporation, College Station, Tx) and performed the chi-square or Fisher's exact test to compare the distribution of CNV regions between cases and controls. False discovery rate (FDR) was used for multiple comparisons correction. $p$ values less than 0.05 was considered statistically significant.

\section{Results}

\section{Design of ASD-specific BAC array}

We developed a ASD-specific BAC array named 'MacArray Karyo Autism Prototype' which covers a total of $27 \mathrm{CNV}$ regions that have been reported to be asso-

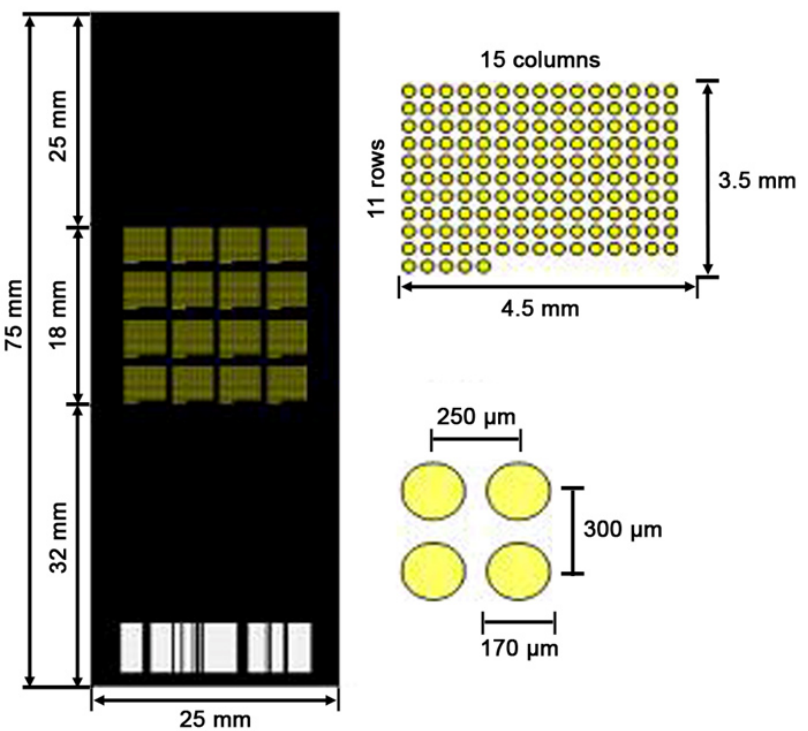

Fig. 1. MacArray Karyo Autism Prototype. We developed an ASD-specific BAC array named 'MacArray Karyo Autism Prototype' which would cover a total of 27 CNV regions that have been reported to be associated with autism in previous studies. The array is 75 by $25 \mathrm{~mm}$ which contains 846 spots with diameter of $0.17 \mathrm{~mm}$ and applied in triplicate. ciated with autism in previous studies including ours (Cho et al., 2009; Klauck, 2006; Schellenberg et al., 2006; Sultana et al., 2002; Vorstman et al., 2006). A total of 846 BAC clones representing the candidate 27 CNV regions were selected for designing ASD-specific BAC array (Fig. 1). Locus specificities of selected clones were improved by removing multiple loci-binding clones under standard fluorescence in situ hybridization (FISH). The information about those targeted 27 genomic regions and 846 BAC clones is available in Supplementary data 1.

\section{CNVs distributed differently between ASDs and normal controls}

Among the 846 BAC clones, 77 spots (15 loci) showed CNVs in at least 2 study participants. Details of the CNV profiles of the 8 ASDs and 10 normal controls for the 77 spots are available in supplementary data 2. Of the 77 spots, a CNV-loss on 8p23.1 (BAC168_A06) was found to be significantly more frequent in ASD patients (7 out of 8 ASD patients versus none in controls, $p<$ 0.0001 ) (Table 2). Two other CNVs were distributed differently between patients and controls, but not significant. A CNV-loss on 17p11.2 (BAC130_G23) was found in 3 out of 8 ASD patients, but not in controls $(p=0.069)$. A CNV-gain on Xp22.31 (BAC231_F19) was found in 4 out of 10 controls, but not in ASDs $(p=0.092)$ (Table 2).

\section{Validation of CNVs on 8p23.1 and 17p11.2 in ASD patients}

The most significant CNV region (BAC168_A06, 8p23.1) contains two coding genes, DEFA1 and DEFA3, which are members of DEFENSIN gene family. Interestingly, the copy number loss CNV on 8p23.1 was identified in all four different ethnic groups and also consistent in duplicated experiments. Fig. 2 shows the examples of CNVs on 8p23.1 and 17p11.2 in ASD patients, which are duplicated and dye swapped and no CNVs in normal control individuals.

Table 2. CNV regions distributed differently between ASDs and normal controls

\begin{tabular}{|c|c|c|c|c|c|c|c|}
\hline \multirow{3}{*}{ Location of CNV } & \multirow{3}{*}{ BAC clone } & \multicolumn{3}{|c|}{ ASD cases $(n=8)$} & \multicolumn{3}{|c|}{ Normal control $(n=10)$} \\
\hline & & \multicolumn{2}{|c|}{ CNV } & \multirow{2}{*}{ No CNV } & \multicolumn{2}{|c|}{ CNV } & \multirow{2}{*}{ No CNV } \\
\hline & & Loss & Gain & & Loss & Gain & \\
\hline $8 p 23.1$ & BAC168_A06 & 7 & 0 & 1 & 0 & 3 & 7 \\
\hline 17p11.2 & BAC130_G23 & 3 & 0 & 5 & 0 & 0 & 10 \\
\hline Xp22.31 & BAC231_F19 & 0 & 0 & 8 & 0 & 4 & 6 \\
\hline
\end{tabular}



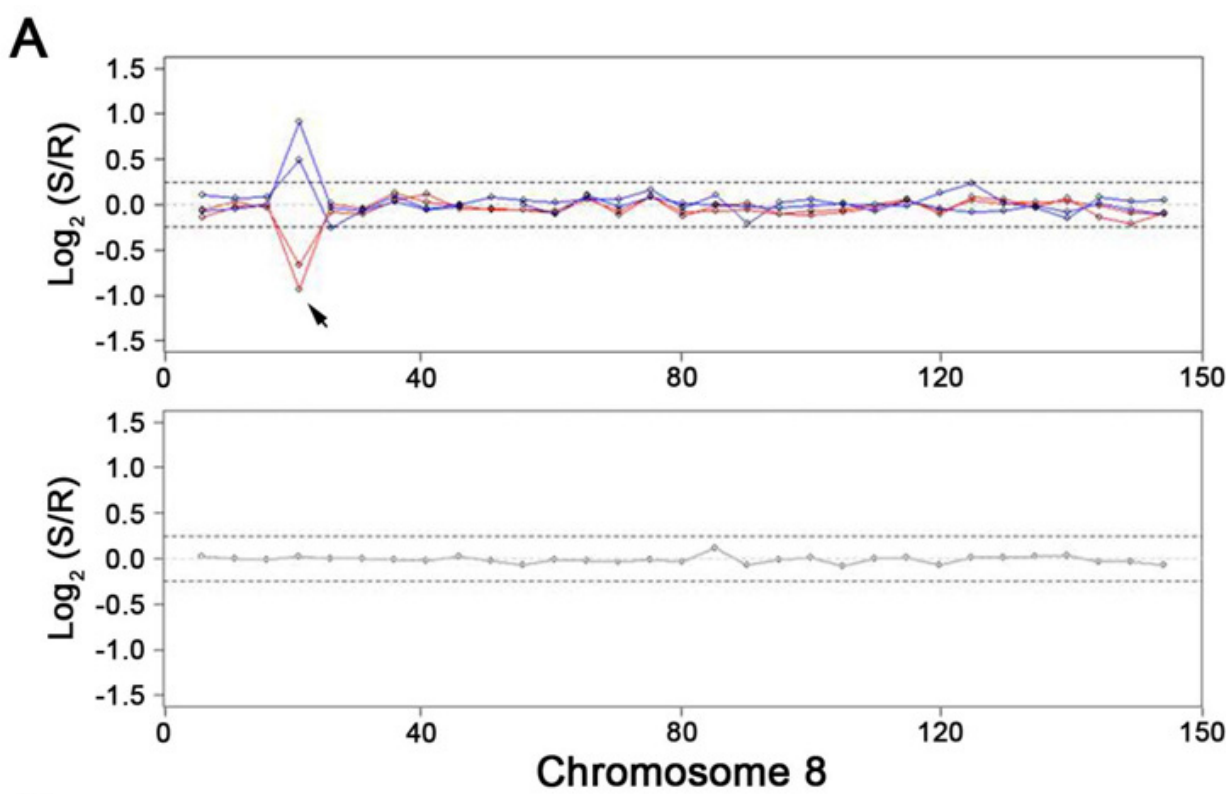

B
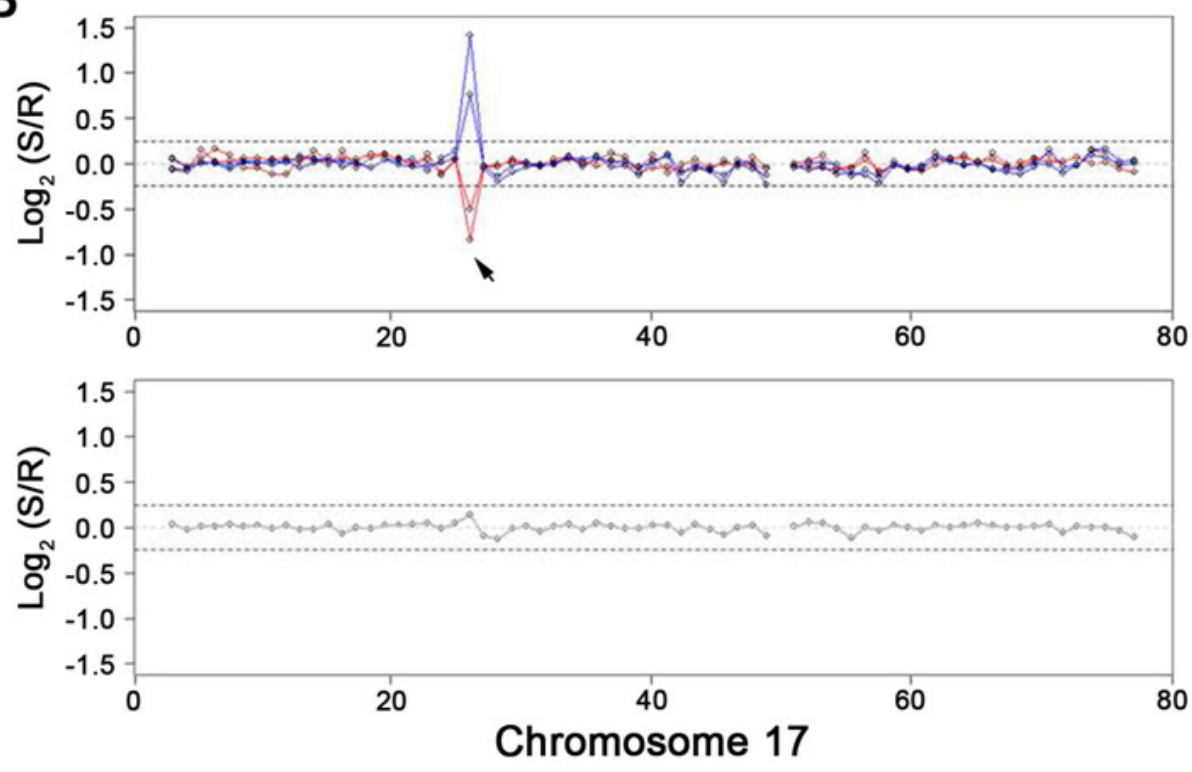

Fig. 2. Examples of copy number loss CNV on 8p23.1 and 17p11.2. (A) A copy number loss on $8 q 23.1$ region from a patient, AU10000 (upper box) and from a normal control, LSG0001 (lower box). (B) A copy number loss on 17p11.2 region from a patient, AU10114 (upper box) and from a normal control, LSG0001 (lower box). Test and reference DNAs were labeled with Сy3 and Cy5, respectively, and cohybridized. Then, the same test and reference DNAs were labeled by switching the dyes. Red graph represents test/reference ratio, copy number loss. Blue graph represent dye swapped ratio. To get more reliable interpretation, the dye swap experiment was repeated two times. Dotted horizontal lines indicate cut-off values that determine copy number changes (0.25 for copy number gain and -0.25 for copy number loss). Arrow heads indicate the CNVs on 8p23.1 and $17 p 11.2$.

\section{Discussion}

It has been widely accepted that ASD has a strong genetic background (Folstein and Rosen-Sheidley, 2001; Rutter, 2005; Veenstra-VanderWeele and Cook, 2004). Although genomic loci or genes reported to be associated with ASD were not easily replicated in subsequent studies for many reasons such as disease heterogeneity per se and relatively high noise levels of genomics technology used, some of the ASD-associated CNVs have been successfully replicated. For example, CNVs in NRXN1, NLGN4 and SHANK3 genes, which had been identified in target gene studies, were replicated in genome-wide CNV studies for ASD (Glessner et al., 2009; Marshall et al., 2008). Given that SNPs or other genetic markers were not very consistent in ASD, this suggests that structural variation could be a more consistent and important marker in ASD and facilitate the elucidation of genetic mechanisms behind the disease.

In our previous study, we identified 38 CNV regions in 28 Korean ASD patients and two of them (CNVs on 8p23.1 and 17p11.2) were significantly associated with ASD. In this study, we designed and prepared an ASD-specific BAC array for CNV analysis and examined 
whether the significant CNV markers would be replicated in independent ASD patients of diverse ethnic origins.

The ASD-specific BAC array contains the two significant CNV regions identified in our previous study and also 25 putative ASD-associated regions reported by previous linkage studies (Cho et al., 2009; Klauck, 2006; Rutter, 2005; Schellenberg et al., 2006; Sultana et al., 2002; Vorstman et al., 2006). However, all 25 candidate regions suggested by linkage analyses were not replicated in our study population. This data seems coherent with previous observations that positive findings from one linkage study often fail to replicate in the other observation (Glessner et al., 2009), but it could be due to small sample size of the study.

In this study, the association of copy number loss CNV on 8p23.1 with ASD was consistently replicated in diverse ethnic groups. 8 p23.1 locus is known to be a frequent region of DNA structural variation in human (Hollox et al., 2008a). DEFENSIN gene family, which is a well-known component of innate immunity, is clustered in this region (Ganz, 1999; Hollox et al., 2008a). CNV of DEFENSIN family, especially beta-defensin, has been reported as a risk factor for different diseases such as psoriasis, Crohn's disease and cystic fibrosis (Hollox, 2008b; Hollox et al., 2008c), which suggests that CNV of DEFENSIN family is likely to be associated with autoimmune diseases. Immunological dysfunction has been suggested to be associated with autism (Folstein and Rosen-Sheidley, 2001; Rutter, 2005) and the copy number loss on $8 \mathrm{p} 23.1$ was reported to be associated with behavioral problems or mental slowness (Pettenati et al., 1992). When this evidence is considered, the association between ASD and CNV of DEFENSIN gene seems worthy of further exploration to elucidate the pathogenesis of ASD. Validation studies with a larger sample size will be required to verify its biological implication.

\section{Acknowledgement}

This study was supported by a grant of Korea Health 21 R\&D Project, Ministry of Health and Welfare, Republic of Korea (0405-BC02-0604-0004).

\section{References}

Cho, S.C., Yim, S.H., Yoo, H.K., Kim, M.Y., Jung, G.Y., Shin, G.W., Kim, B.N., Hwang, J.W., Kang, J.J., Kim, T.M., and Chung, Y.J. (2009). Copy number variations associated with idiopathic autism identified by whole-genome microarray-based comparative genomic hybridization. Psychiatr. Genet. 19, 177-185.

Chung, Y.J., Jonkers, J., Kitson, H., Fiegler, H., Humphray,
S., Scott, C., Hunt, S., Yu, Y., Nishijima, I., Velds, A., Holstege, H., Carter, N., and Bradley, A. (2004). A whole-genome mouse BAC microarray with 1-Mb resolution for analysis of DNA copy number changes by array comparative genomic hybridization. Genome Res. 14, 188-196

Cook, E.H.Jr., and Scherer, S.W. (2008). Copy-number variations associated with neuropsychiatric conditions. Nature 455, 919-923.

Folstein, S.E., and Rosen-Sheidley, B. (2001). Genetics of autism: complex aetiology for a heterogeneous disorder. Nat. Rev. Genet. 2, 943-955.

Freeman, J.L., Perry, G.H., Feuk, L., Redon, R., McCarroll, S.A., Altshuler, D.M., Aburatani, $H_{\text {., }}$ Jones, K.W., Tyler-Smith, C., Hurles, M.E., Carter, N.P., Scherer, S.W., and Lee, C. (2006). Copy number variation: new insights in genome diversity. Genome Res, 16, 949-961.

Ganz, T. (1999). Defensins and host defense. Science 286, 420-421.

Glessner, J.T., Wang, K., Cai, G., Korvatska, O., Kim, C.E., Wood, S., Zhang, H., Estes, A., Brune, C.W., Bradfield, J.P., Imielinski, M., Frackelton, E.C., Reichert, J., Crawford, E.L., Munson, J., Sleiman, P.M., Chiavacci, R., Annaiah, K., Thomas, K., Hou, C., Glaberson, W., Flory, J., Otieno, F., Garris, M., Soorya, L., Klei, L., Piven, J,, Meyer, K.J., Anagnostou, E., Sakurai, T., Game, R.M., Rudd, D.S., Zurawiecki, D., McDougle, C.J., Davis, L.K., Miller, J., Posey, D.J., Michaels, S., Kolevzon, A., Silverman, J.M., Bernier, R., Levy, S.E., Schultz, R.T., Dawson, G., Owley, T., McMahon, W.M., Wassink, T.H.,

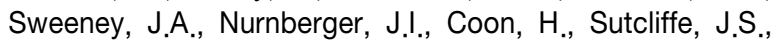
Minshew, N.J., Grant, S.F., Bucan, M., Cook, E.H., Buxbaum, J.D., Devlin, B., Schellenberg, G.D., and Hakonarson, H. (2009). Autism genome-wide copy number variation reveals ubiquitin and neuronal genes. Nature 459, 569-573.

Hollox, E.J. (2008b). Copy number variation of beta-defensins and relevance to disease. Cytogenet. Genome Res. 123, 148-155.

Hollox, E.J., Barber, J.C., Brookes, A.J., and Armour, J.A. (2008a). Defensins and the dynamic genome: what we can learn from structural variation at human chromosome band 8p23.1. Genome Res. 18, 1686-1697.

Hollox, E.J., Huffmeier, U., Zeeuwen, P.L., Palla, R., Lascorz, J., Rodijk-Olthuis, D., van de Kerkhof, P.C.,

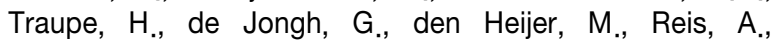
Armour, J.A., and Schalkwijk, J. (2008c). Psoriasis is associated with increased beta-defensin genomic copy number. Nat. Genet. 40, 23-25.

lafrate, A.J., Feuk, L., Rivera, M.N., Listewnik, M.L., Donahoe, P.K., Qi, Y., Schererm S.W., and Lee, C. (2004). Detection of large-scale variation in the human genome. Nat. Genet. 36, 949-951.

Jeong, Y.B., Kim, T.M., and Chung, Y.J. (2008). CGHscape: A Software Framework for the Detection and Visualization of Copy Number Alterations. Genomics Inform. 6, 126-129.

Joo, H.J., Jung, S.H., Yim, S.H., Kim, T.M., Xu, H.D., Shin, S.H., Kim, M.Y., Kang, H.M., and Chung, Y.J. (2008). 
Comparison of Non-amplified and Amplified DNA Preparation Methods for Array-comparative Gnomic Hybridization Analysis. Mol. Cell. Toxicol, 4, 246-252.

Klauck, S.M. (2006). Genetics of autism spectrum disorder. Eur. J. Hum. Genet. 14, 714-720.

Marshall, C.R., Noor, A., Vincent, J.B., Lionel, A.C., Feuk, L., Skaug, J., Shago, M., Moessner, R., Pinto, D., Ren, Y., Thiruvahindrapduram, B., Fiebig, A., Schreiber, S., Friedman, J., Ketelaars, C.E., Vos, Y.J., Ficicioglu, C., Kirkpatrick, S., Nicolson, R., Sloman, L., Summers, A., Gibbons, C.A., Teebi, A., Chitayat, D., Weksberg, R., Thompson, A., Vardy, C., Crosbie, V., Luscombe, S., Baatjes, R., Zwaigenbaum, L., Roberts, W., Fernandez, B., Szatmari, P., and Scherer, S.W. (2008). Structural variation of chromosomes in autism spectrum disorder. $\mathrm{Am}$. J. Hum. Genet. 82, 477-488.

Pettenati, M.J., Rao, N., Johnson, C., Hayworth, R., Crandall, K., Huff, O., and Thomas, I.T. (1992). Molecular cytogenetic analysis of a familial 8p23.1 deletion associated with minimal dysmorphic features, seizures, and mild mental retardation. Hum. Genet. 89, 602-606.

Rutter, M. (2005). Autism research: lessons from the past and prospects for the future. J. Autism. Dev. Disord. 35, 241-257.

Schellenberg, G.D., Dawson, G., Sung, Y.J., Estes, A., Munson, J., Rosenthal, E., Rothstein, J., Flodman, P., Smith, M., Coon, H., Leong, L., Yu, C.E., Stodgell, C., Rodier, P.M., Spence, M.A., Minshew, N., McMahon, W.M., and Wijsman, E.M. (2006). Evidence for multiple loci from a genome scan of autism kindreds. Mol. Psychiatry 11, 1049-1160.

Sebat, J., Lakshmi, B., Malhotra, D., Troge, J., Lese-Martin,
C., Walsh, T., Yamrom, B., Yoon, S., Krasnitz, A., Kendall, J., Leotta, A., Pai, D., Zhang, R., Lee, Y.H., Hicks, J., Spence, S.J., Lee, A.T., Puura, K., Lehtim?ki, T., Ledbetter, D., Gregersen, P.K., Bregman, J., Sutcliffe, J.S., Jobanputra, V., Chung, W., Warburton, D., King, M.C., Skuse, D., Geschwind, D.H., Gilliam, T.C., Ye, K., and Wigler, M. (2007). Strong association of de novo copy number mutations with autism. Science 316, 445-449.

Sebat, J., Lakshmi, B., Troge, J., Alexander, J., Young, J., Lundin, P., Månér, S., Massa, H., Walker, M., Chi, M., Navin, N., Lucito, R., Healy, J., Hicks, J., Ye, K., Reiner, A., Gilliam, T.C., Trask, B., Patterson, N., Zetterberg, A., and Wigler, M. (2004). Large-scale copy number polymorphism in the human genome. Science 305, 525-528.

Sultana, R., Yu, C.E., Yu, J., Munson, J., Chen, D., Hua, W., Estes, A., Cortes, F., de la Barra, F., Yu, D., Haider, S.T., Trask, B.J., Green, E.D., Raskind, W.H., Disteche, C.M., Wijsman, E., Dawson, G., Storm, D.R., Schellenberg, G.D., and Villacres, E.C. (2002). Identification of a novel gene on chromosome $7 q 11.2$ interrupted by a translocation breakpoint in a pair of autistic twins. Genomics 80, 129-134.

Veenstra-VanderWeele, J., and Cook, E.H.Jr. (2004). Molecular genetics of autism spectrum disorder. Mol. Psychiatry 9, 819-832.

Vorstman, J.A., Staal, W.G., van Daalen, E., van Engeland, H., Hochstenbach, P.F., and Franke, L. (2006). Identification of novel autism candidate regions through analysis of reported cytogenetic abnormalities associated with autism. Mol. Psychiatry 11, 18-28. 
Supplementary data 1. Twenty-seven targeted regions of MacArray Karyo Autism Prototype

\begin{tabular}{lrrc}
\hline Cytoband & Start $(\mathrm{bp})$ & End(bp) & $\begin{array}{c}\text { \# of BAC clones } \\
\text { for detection }\end{array}$ \\
\hline $1 \mathrm{q} 23.2$ & 157300000 & 158800000 & 9 \\
$2 \mathrm{q} 31.1$ & 169500000 & 177700000 & 50 \\
$3 \mathrm{p} 25.2$ & 11500000 & 12400000 & 6 \\
$4 \mathrm{q} 23$ & 99100000 & 102500000 & 15 \\
$5 \mathrm{p} 15.33$ & 1 & 4400000 & 27 \\
$6 \mathrm{q} 22.1$ & 113900000 & 117100000 & 17 \\
$7 \mathrm{q} 22.1$ & 97900000 & 104400000 & 47 \\
$7 \mathrm{q} 36.1$ & 147500000 & 152200000 & 36 \\
$7 \mathrm{q} 36.2$ & 152200000 & 154700000 & 16 \\
$8 \mathrm{p} 23.1$ & 6200000 & 12700000 & 31 \\
$9 \mathrm{p} 24.1$ & 4600000 & 9000000 & 22 \\
$11 \mathrm{p} 13$ & 31000000 & 36400000 & 33 \\
$11 \mathrm{q} 25$ & 130300000 & 134452384 & 37 \\
$15 \mathrm{q} 23$ & 65300000 & 70400000 & 39 \\
$15 \mathrm{q} 24$ & 70400000 & 76100000 & 39 \\
$15 \mathrm{q} 25$ & 76100000 & 86900000 & 56 \\
$16 \mathrm{p} 13.13$ & 10300000 & 12500000 & 13 \\
$16 \mathrm{2} 22.3$ & 69800000 & 73300000 & 29 \\
$17 \mathrm{p} 11.2$ & 15900000 & 22100000 & 23 \\
$17 \mathrm{q} 11.2$ & 23200000 & 28800000 & 47 \\
$18 \mathrm{q} 21.1$ & 41800000 & 46400000 & 35 \\
$18 \mathrm{q} 23$ & 71300000 & 76117153 & 38 \\
$19 \mathrm{p} 13.12$ & 13800000 & 16100000 & 11 \\
$22 \mathrm{1} 11.2$ & 16300000 & 24300000 & 52 \\
$22 \mathrm{q} 13.3$ & 42600000 & 49691432 & 54 \\
Xp22.3 & 1 & 9500000 & 33 \\
Xp22.2 & 9500000 & 17100000 & 31 \\
\hline \multicolumn{1}{c}{ Total } & & & 846 \\
\hline & & & \\
\hline
\end{tabular}


26 Genomics \& Informatics Vol. 8(1) 19-27, March 2010

Supplementary data 2. Copy number variations identified in ASD cases and normal controls

\begin{tabular}{|c|c|c|c|c|c|c|c|c|}
\hline \multirow[b]{2}{*}{ Chr } & \multirow{2}{*}{ Clone ID } & \multirow{2}{*}{ Cytoband } & \multirow{2}{*}{ start (Mb) } & \multirow{2}{*}{ end $(\mathrm{Mb})$} & \multicolumn{2}{|c|}{ ASD $(n=8)$} & \multicolumn{2}{|c|}{ Control $(n=10)$} \\
\hline & & & & & Gain & Loss & Gain & Loss \\
\hline 7 & BAC127_M11 & $7 q 22.1$ & 98.53 & 98.63 & 0 & 0 & 0 & 2 \\
\hline 7 & BAC247_E05 & $7 q 22.1$ & 100.41 & 100.48 & 0 & 0 & 0 & 2 \\
\hline 7 & BAC165_L12 & $7 q 22.1$ & 101.38 & 101.46 & 0 & 0 & 0 & 2 \\
\hline 8 & BAC168_A06 & $8 p 23.1$ & 6.8 & 6.87 & 0 & 7 & 3 & 0 \\
\hline 8 & BAC135_H20 & $8 p 23.1$ & 7.33 & 7.42 & 1 & 2 & 1 & 1 \\
\hline 8 & BAC194_P23 & $8 p 23.1$ & 8.6 & 8.7 & 0 & 0 & 3 & 0 \\
\hline 8 & BAC64_D05 & $8 p 23.1$ & 11.65 & 11.77 & 0 & 0 & 3 & 0 \\
\hline 11 & BAC127_F16 & $11 \mathrm{p} 13$ & 31.37 & 31.45 & 0 & 0 & 2 & 0 \\
\hline 11 & BAC209_B17 & $11 \mathrm{p} 13$ & 32.37 & 32.48 & 0 & 0 & 3 & 0 \\
\hline 11 & BAC149_C22 & $11 q 25$ & 132.76 & 132.84 & 0 & 0 & 2 & 0 \\
\hline 11 & BAC134_M14 & $11 q 25$ & 133.52 & 133.62 & 0 & 0 & 3 & 0 \\
\hline 15 & BAC194_M03 & $15 q 24.1$ & 70.75 & 70.85 & 0 & 0 & 0 & 2 \\
\hline 17 & BAC130_G23 & $17 p 11.2$ & 21.83 & 21.85 & 0 & 3 & 0 & 0 \\
\hline 17 & BAC208_O06 & $17 q 11.2$ & 23.59 & 23.71 & 0 & 0 & 0 & 3 \\
\hline 18 & BAC56_016 & $18 q 23$ & 75.84 & 76.01 & 0 & 0 & 3 & 0 \\
\hline 19 & BAC132_015 & $19 \mathrm{p} 13.12$ & 15.97 & 16.1 & 0 & 0 & 0 & 2 \\
\hline 22 & BAC185_K22 & $22 q 11.21$ & 17.65 & 17.73 & 0 & 0 & 2 & 0 \\
\hline 22 & BAC17_E13 & $22 q 11.22$ & 21.33 & 21.44 & 0 & 2 & 0 & 0 \\
\hline 22 & BAC172_P19 & $22 q 13.31$ & 43.97 & 44.05 & 0 & 0 & 0 & 3 \\
\hline$x$ & BAC195_D03 & Xp22.33 & 2.78 & 2.88 & 1 & 0 & 1 & 0 \\
\hline$x$ & BAC32_O13 & Xp22.33 & 2.78 & 2.89 & 1 & 0 & 2 & 0 \\
\hline$x$ & BAC55_C05 & Xp22.33 & 2.8 & 2.96 & 0 & 0 & 2 & 0 \\
\hline$x$ & BAC170_E06 & Xp22.33 & 2.89 & 2.98 & 1 & 0 & 2 & 0 \\
\hline$x$ & BAC119_C10 & Xp22.33 & 3.26 & 3.35 & 1 & 0 & 2 & 0 \\
\hline$x$ & BAC172_C15 & Xp22.33 & 4.02 & 4.11 & 0 & 0 & 2 & 0 \\
\hline$x$ & BAC38_L03 & Xp22.32 & 4.41 & 4.55 & 2 & 0 & 2 & 0 \\
\hline$x$ & BAC14_K21 & Xp22.32 & 4.61 & 4.71 & 1 & 0 & 3 & 0 \\
\hline$x$ & BAC226_K11 & Xp22.32 & 4.83 & 4.93 & 1 & 0 & 3 & 0 \\
\hline$x$ & BAC165_G03 & Xp22.32 & 5.03 & 5.13 & 0 & 0 & 2 & 0 \\
\hline$x$ & BAC204_C10 & Xp22.32 & 5.12 & 5.22 & 1 & 0 & 2 & 0 \\
\hline$x$ & BAC247_D06 & Xp22.32 & 5.63 & 5.72 & 1 & 0 & 2 & 0 \\
\hline$x$ & BAC28_F18 & Xp22.32 & 5.8 & 6.02 & 1 & 0 & 2 & 0 \\
\hline$x$ & BAC37_K21 & Xp22.31 & 6.09 & 6.19 & 1 & 0 & 3 & 0 \\
\hline$x$ & BAC243_C15 & Xp22.31 & 6.6 & 6.68 & 1 & 0 & 4 & 0 \\
\hline$x$ & BAC221_A12 & Xp22.31 & 7.09 & 7.19 & 1 & 0 & 4 & 0 \\
\hline$x$ & BAC191_E24 & Xp22.31 & 7.4 & 7.5 & 1 & 0 & 4 & 0 \\
\hline$x$ & BAC231_F19 & Xp22.31 & 7.55 & 7.64 & 0 & 0 & 4 & 0 \\
\hline$x$ & BAC31_E12 & Xp22.31 & 7.61 & 7.73 & 2 & 0 & 5 & 0 \\
\hline$x$ & BAC26_J10 & Xp22.31 & 7.86 & 7.96 & 1 & 0 & 3 & 0 \\
\hline$x$ & BAC177_015 & Xp22.31 & 8.24 & 8.35 & 2 & 0 & 3 & 0 \\
\hline$x$ & BAC185_C21 & Xp22.31 & 8.55 & 8.66 & 1 & 0 & 2 & 0 \\
\hline$x$ & BAC178_N11 & Xp22.31 & 8.57 & 8.66 & 0 & 0 & 2 & 0 \\
\hline$x$ & BAC170_I18 & Xp22.31 & 8.58 & 8.66 & 0 & 0 & 3 & 0 \\
\hline$x$ & BAC58_F06 & Xp22.31 & 8.58 & 8.68 & 2 & 0 & 2 & 0 \\
\hline$x$ & BAC175_B18 & Xp22.31 & 8.64 & 8.74 & 1 & 0 & 2 & 0 \\
\hline$x$ & BAC135_L05 & Xp22.31 & 8.65 & 8.73 & 1 & 0 & 3 & 0 \\
\hline$x$ & BAC201_I22 & Xp22.31 & 8.94 & 9.02 & 0 & 0 & 2 & 1 \\
\hline$x$ & BAC180_P24 & Xp22.31 & 9.1 & 9.23 & 2 & 0 & 3 & 0 \\
\hline$x$ & BAC252_L05 & Xp22.2 & 9.52 & 9.65 & 1 & 0 & 3 & 0 \\
\hline$x$ & BAC153_J20 & Xp22.2 & 9.78 & 9.81 & 1 & 0 & 1 & 0 \\
\hline$x$ & BAC224_E17 & Xp22.2 & 9.8 & 9.88 & 2 & 0 & 3 & 0 \\
\hline$x$ & BAC143_P20 & Xp22.2 & 10.21 & 10.3 & 1 & 0 & 2 & 0 \\
\hline$x$ & BAC165_B04 & Xp22.2 & 10.43 & 10.53 & 2 & 0 & 2 & 0 \\
\hline$x$ & BAC181_H09 & Xp22.2 & 10.65 & 10.75 & 1 & 0 & 3 & 0 \\
\hline
\end{tabular}


Supplementary data 2. Contined

\begin{tabular}{|c|c|c|c|c|c|c|c|c|}
\hline \multirow{2}{*}{ Chr } & \multirow{2}{*}{ Clone ID } & \multirow{2}{*}{ Cytoband } & \multirow{2}{*}{ start (Mb) } & \multirow{2}{*}{ end $(\mathrm{Mb})$} & \multicolumn{2}{|c|}{ ASD $(n=8)$} & \multicolumn{2}{|c|}{ Control $(n=10)$} \\
\hline & & & & & Gain & Loss & Gain & Loss \\
\hline$x$ & BAC121_N22 & Xp22.2 & 11.13 & 11.21 & 2 & 0 & 2 & 0 \\
\hline$x$ & BAC166_K19 & Xp22.2 & 11.21 & 11.3 & 1 & 0 & 2 & 0 \\
\hline$x$ & BAC247_L21 & Xp22.2 & 11.4 & 11.47 & 1 & 0 & 2 & 0 \\
\hline$x$ & BAC151_D12 & Xp22.2 & 11.54 & 11.62 & 1 & 0 & 3 & 0 \\
\hline$x$ & BAC51_J21 & Xp22.2 & 11.85 & 11.99 & 1 & 0 & 2 & 0 \\
\hline$x$ & BAC31_M18 & Xp22.2 & 12.17 & 12.25 & 2 & 0 & 3 & 0 \\
\hline$x$ & BAC81_D07 & Xp22.2 & 12.43 & 12.53 & 1 & 0 & 2 & 0 \\
\hline$x$ & BAC194_L05 & Xp22.2 & 12.63 & 12.73 & 2 & 0 & 2 & 0 \\
\hline$x$ & BAC162_J15 & Xp22.2 & 12.81 & 12.93 & 1 & 0 & 2 & 0 \\
\hline$x$ & BAC72_G18 & Xp22.2 & 12.87 & 12.95 & 1 & 0 & 2 & 0 \\
\hline$x$ & BAC172_E18 & Xp22.2 & 13.32 & 13.42 & 2 & 0 & 3 & 0 \\
\hline$x$ & BAC161_F20 & Xp22.2 & 13.46 & 13.57 & 1 & 0 & 2 & 0 \\
\hline$x$ & BAC19_P08 & Xp22.2 & 13.56 & 13.66 & 0 & 0 & 3 & 0 \\
\hline$x$ & BAC236_M15 & Xp22.2 & 14.43 & 14.52 & 1 & 0 & 3 & 0 \\
\hline$x$ & BAC33_D22 & Xp22.2 & 14.76 & 14.85 & 1 & 0 & 3 & 0 \\
\hline$x$ & BAC107_A08 & Xp22.2 & 15.39 & 15.54 & 2 & 0 & 3 & 0 \\
\hline$x$ & BAC39_M09 & Xp22.2 & 15.43 & 15.52 & 2 & 0 & 3 & 0 \\
\hline$x$ & BAC122_M06 & Xp22.2 & 15.59 & 15.68 & 1 & 0 & 3 & 0 \\
\hline$x$ & BAC244_J12 & Xp22.2 & 15.66 & 15.73 & 1 & 0 & 2 & 0 \\
\hline$x$ & BAC184_J09 & Xp22.2 & 16.29 & 16.37 & 1 & 0 & 3 & 0 \\
\hline$x$ & BAC31_022 & Xp22.2 & 16.56 & 16.65 & 1 & 0 & 2 & 0 \\
\hline$x$ & BAC230_P12 & Xp22.2 & 16.89 & 17 & 1 & 0 & 2 & 0 \\
\hline$x$ & BAC155_G06 & Xp22.2 & 17 & 17.09 & 1 & 0 & 2 & 0 \\
\hline
\end{tabular}

